considerable difference in the level of complaints about heavy bleeding suggests that women suffering from minor psychiatric illness are more likely to present as possible candidates for hysterectomy, and this may account, at least partly, for the excess psychiatric morbidity reported after hysterectomy.

I thank Drs. Jean Ferguson, John Ferguson, E. D. B. Denovan, J. B. Malcolm, W. H. Gossip, and Carol Henderson for permission to approach their patients and helpful advice; and Professor I. R. C. Batchelor and Professor James Walker for their advice and help in the preparation of this paper.

\section{References \\ 1 Slater, E., and Roth, M., Clinical Psychiatry. London, Bailliere, Tindall, and Cassell, 1969.}

${ }^{2}$ Mitchell, A. R. K., Psychological Medicine in Family Practice. London, Bailliere Tindall, 1971.

${ }^{3}$ Jeffcoate, T. N. A., British Medical fournal, 1960, 1, 340.

${ }^{4}$ Malleson, J., Lancet, 1953, 2, 158.

5 Malleson, J., British Medical fournal, 1956, 2, 1422.

${ }^{6}$ Wilson, R. A., and Wilson, T. A., fournal of the American Geriatric Society, 1963, 11, 347.

${ }^{7}$ Neugarten, B. L., and Kraines, R. J., Psychosomatic Medicine, 1965, 27, 266.

${ }^{8}$ McKinlay, S. M., and Jeffreys, M., British Fournal of Preventive and Social Medicine, 1974, 28, 108.

9 Jaszmann, L., et al., Medical Gynaecology and Sociology, 1969, 4, 268.

10 Goldberg, D. P., The Detection of Psychiatric Illness by Questionnaire. London, O.U.P., 1972.

11 Goldberg, D. P., and Blackwell, B., British Medical fournal, 1970, 1, 439.

12 Adamopoulos, D. A., Loraine, J. A., and Dove, G. A., Fournal of Obstetrics and Gynaecology of the British Commonwealth, 1971, 78, 62.

13 Barker, M. G., British Medical fournal, 1968, 2, 91.

14 Richards, D. H., Lancet, 1973, 2, 430.

\title{
Sleep and Blood Pressure
}

\author{
W. A. LITTLER, \\ British Medical fournal, 1975, 3, 346-348
}

A. J. HONOUR,

R. D. CARTER,

\begin{abstract}
Summary
Direct arterial pressure was recorded continuously over 24 hours in 18 totally unrestricted people (six normotensives, four untreated hypertensives, and eight treated hypertensives). There was an almost equal fall of about $20 \%$ in both systolic and diastolic blood pressure during sleep in the three groups when compared with their waking pressures. This fall in pressure was greater than that observed previously in patients sleeping in a laboratory or hospital. Furthermore, it suggests that hypertensive subjects do not have a higher centrally-induced vasoactive component and that hypotensive drugs do not alter the pattern of blood pressure behaviour induced by sleep.
\end{abstract}

\section{Introduction}

Changes in the circulation during sleep have been investigated since Galen's time. The general picture that emerges ${ }^{1-5}$ is that blood pressure falls during sleep, often profoundly, with the lowest pressures during the early part of sleep. In people with high blood pressure the absolute fall in pressure is even greater, while dreaming may be associated with transient increases and a much greater variability of pressure. Events within the central nervous system concurrent with the onset of sleep have been thought to be responsible for a greater fall in arterial pressure than can be accounted for by simple rest in the recumbent

University Department of Cardiovascular Medicine, Radcliffe Infirmary, Oxford OX2 6HE

W. A. LITTLER, M.D., M.R.C.P., Lecturer

P. SLEIGHT, M.D., F.R.C.P., Professor

Department of the Regius Professor of Medicine, Radcliffe Infirmary, Oxford OX2 6HE

A. J. HONOUR, M.A., D.PHIL., First Assistant

R. D. CARTER, A.I.S.r., Technician

\section{P. SLEIGHT}

position, since bradycardia and a fall in blood pressure follow closely on the disappearance of the alpha rhythm of the electroencephalograph (E.E.G.) during light sleep.

Studies on the cardiovascular changes during sleep have, with one exception, ${ }^{6}$ been undertaken in laboratories or hospitals and, while all agree that arterial pressure falls, results have differed with regard to changes in heart rate, cardiac output, and total peripheral resistance. ${ }^{45}$ The degree of fall of arterial pressure during sleep reported has not been uniform. Bristow et al. ${ }^{5}$ and Khatri and Freis ${ }^{4}$ found that mean arterial pressure fell some $7-12 \%$ from waking levels in both normotensive and hypertensive patients, while Richardson et al. ${ }^{3}$ noted a fall of about $19 \%$ in both systolic and diastolic pressure in normotensive people compared with a $12 \%$ fall in hypertensive patients. A similar discrepancy was noted by Bevan et al. ${ }^{6}$ who found that systolic and diastolic pressures in untreated hypertensive patients fell by $5 \%$ and $2 \%$ respectively compared with $10 \%$ and $17 \%$ in normotensive people; furthermore, in four normotensive subjects who slept at home the fall was even greater, averaging 25\% (systolic) and 30\% (diastolic).

We report here the changes in arterial pressure during sleep which occurred in 18 people whose blood pressure was measured continuously over 24 hours and who all slept in their own homes.

\section{Subjects and Methods}

Eighteen patients were chosen from a group in whom direct arterial pressure, heart rate, and electrocardiogram were recorded continuously over 24 hours because they all slept at home and indicated that they had had a "normal" night's sleep. They gave their informed consent to the study. The methods used for measuring direct arterial pressure in unrestricted patients have been fully described elsewhere. ${ }^{7}$ The patients were studied over 24 hours, from 9 a.m. to 9 a.m., during which they attended the laboratory only once for 15 minutes after 12 hours to service the perfusion chamber and calibrate the tape. Significant events were recorded simultaneously on tape and in a diary kept by the patient

Systolic and diastolic pressures were averaged over successive 30 -minute periods throughout the 24 hours. The period of "sleep" was taken as the period from the mark on the tape when the patient indicated that he was in bed to that when he indicated that he was awake. No patient took night sedation, but eight with raised arterial pressure were on treatment (see table). 
Details and Blood Pressure Readings ( \pm 1 S.D.) of 18 subjects. Lowest Single Pressure Achieved during Sleep is also listed

\begin{tabular}{|c|c|c|c|c|c|c|c|c|}
\hline \multirow{2}{*}{$\begin{array}{l}\text { Case } \\
\text { No. }\end{array}$} & \multirow{2}{*}{\multicolumn{2}{|c|}{ Age and Sex }} & \multirow{2}{*}{$\begin{array}{l}\text { Treatment } \\
(\text { Dose } / 24 \mathrm{~h})\end{array}$} & \multicolumn{2}{|c|}{ Arterial Pressure (mm Hg) } & \multirow{2}{*}{$\begin{array}{c}\text { Fall in } \\
\text { Pressure } \\
(\mathrm{mm} \mathrm{Hg})\end{array}$} & \multirow{2}{*}{$\%$ Fall } & \multirow{2}{*}{$\begin{array}{l}\text { Lowest } \\
\text { "Asleep" } \\
\text { Pressure } \\
\text { (mm Hg) }\end{array}$} \\
\hline & & & & Awake & Asleep & & & \\
\hline \multicolumn{9}{|c|}{ Normotensive Subjects } \\
\hline $\begin{array}{l}1 \\
2 \\
3 \\
4 \\
5 \\
6 \\
\end{array}$ & $\begin{array}{l}32 \\
35 \\
21 \\
29 \\
36 \\
32 \\
\end{array}$ & $\begin{array}{l}\mathrm{F} \\
\mathrm{M} . \\
\mathrm{M} . \\
\mathrm{M} . \\
\mathrm{M} . \\
\mathrm{M}\end{array}$ & & $\begin{array}{l}108 / 60 \pm 13 \cdot 8 / 12 \cdot 7 \\
136 / 73 \pm 17 \cdot 8 / 12 \cdot 7 \\
123 / 92 \pm 11 \cdot 4 / 13 \cdot 7 \\
123 / 72 \pm 13 \cdot 0 / 9 \cdot 0 \\
132 / 78 \pm 14 \cdot 6 / 10 \cdot 8 \\
132 / 84 \pm 10 \cdot 4 / 7 \cdot 2\end{array}$ & $\begin{array}{r}86 / 45 \pm 8 \cdot 0 / 6 \cdot 0 \\
102 / 53 \pm 6 \cdot 7 / 6 \cdot 4 \\
100 / 78 \pm 7 \cdot 6 / 8 \cdot 0 \\
99 / 56 \pm 5 \cdot 7 / 4 \cdot 2 \\
110 / 63 \pm 8 \cdot 8 / 5 \cdot 1 \\
111 / 75 \pm 4 \cdot 2 / 4 \cdot 1 \\
\end{array}$ & $\begin{array}{l}22 / 15 \\
34 / 20 \\
23 / 14 \\
24 / 16 \\
22 / 15 \\
21 / 9 \\
\end{array}$ & $\begin{array}{l}20 \cdot 4 / 25 \cdot 0 \\
25 \cdot 0 / 27 \cdot 4 \\
18 \cdot 7 / 15 \cdot 2 \\
25 \cdot 7 / 16 \cdot 5 \\
16 \cdot 7 / 19 \cdot 2 \\
15 \cdot 9 / 10 \cdot 7\end{array}$ & $\begin{array}{l}56 / 13 \\
93 / 35 \\
81 / 55 \\
91 / 43 \\
97 / 29 \\
84 / 52 \\
\end{array}$ \\
\hline Mean & $29 \cdot 1$ & & & $126 / 77$ & $101 / 61$ & $25 / 16$ & $20 \cdot 4 / 19 \cdot 0$ & $84 / 38$ \\
\hline $\begin{array}{r}7 \\
8 \\
9 \\
10\end{array}$ & $\begin{array}{l}41 \\
26 \\
23 \\
61\end{array}$ & $\begin{array}{l}\text { M. } \\
\text { M. } \\
\text { F. } \\
\text { F. }\end{array}$ & & $\begin{array}{l}\text { Untreated } H y \\
208 / 99 \pm 24 \cdot 5 / 12 \cdot 1 \\
141 / 104 \pm 16 \cdot 5 / 17 \cdot 9 \\
176 / 118 \pm 21 \cdot 0 / 11 \cdot 3 \\
196 / 96 \pm 22 \cdot 0 / 21 \cdot 0\end{array}$ & $\begin{array}{l}\text { ve Patients } \\
134 / 78 \pm 14 \cdot 9 / 15 \cdot 8 \\
116 / 87 \pm 9 \cdot 7 / 5 \cdot 9 \\
137 / 88 \pm 11 \cdot 8 / 9 \cdot 5 \\
164 / 71 \pm 15 \cdot 0 / 20 \cdot 0\end{array}$ & $\begin{array}{l}74 / 21 \\
25 / 17 \\
39 / 30 \\
32 / 25\end{array}$ & $\begin{array}{l}35 \cdot 3 / 21 \cdot 2 \\
17 \cdot 7 / 16 \cdot 4 \\
22 \cdot 1 / 25 \cdot 2 \\
16 \cdot 4 / 25 \cdot 5\end{array}$ & $\begin{array}{l}111 / 49 \\
108 / 69 \\
115 / 72 \\
110 / 18 \\
\end{array}$ \\
\hline Mean & \multicolumn{2}{|c|}{$37 \cdot 7$} & & $180 / 104$ & $138 / 81$ & $42 / 23$ & $22 \cdot 9 / 22 \cdot 0$ & $111 / 52$ \\
\hline \multicolumn{9}{|c|}{ Treated Hypertensive Patients } \\
\hline 11 & 29 & M. & $\begin{array}{l}\text { Propanolol } 160 \mathrm{mg} \\
\text { Navidrex } \mathrm{K} 2 \text { tabs. }\end{array}$ & $134 / 77 \pm 12 \cdot 9 / 11 \cdot 8$ & $101 / 58 \pm 6 \cdot 6 / 6 \cdot 5$ & $33 / 21$ & $24 \cdot 8 / 27 \cdot 2$ & $74 / 40$ \\
\hline 12 & 47 & F. & $\begin{array}{l}\text { Methyldopa } 1.5 \mathrm{~g} \\
\text { Bethanidine } 45 \mathrm{mg} \\
\text { Aldactide } 4 \text { tabs. }\end{array}$ & $179 / 102 \pm 17 \cdot 0 / 10 \cdot 6$ & $147 / 84 \pm 8 \cdot 8 / 5 \cdot 4$ & $32 / 18$ & $18 \cdot 0 / 17 \cdot 7$ & $120 / 68$ \\
\hline $\begin{array}{l}13 \\
14\end{array}$ & $\begin{array}{l}64 \\
62\end{array}$ & $\begin{array}{l}\text { F. } \\
\text { F. }\end{array}$ & $\begin{array}{l}\text { Aldactide } 2 \text { tabs. } \\
\text { Bethanidine } 50 \mathrm{mg} \\
\text { Hydrallazine } 100 \mathrm{mg} \\
\text { Propanolol } 240 \mathrm{mg} \\
\text { Navidrex K2 tabs. }\end{array}$ & $\begin{array}{l}169 / 82 \pm 21 \cdot 3 / 10 \cdot 2 \\
143 / 71 \pm 20 \cdot 2 / 12 \cdot 9\end{array}$ & $\begin{array}{l}138 / 71 \pm 15 \cdot 5 / 10 \cdot 0 \\
119 / 54 \pm 13 \cdot 0 / 6 \cdot 5\end{array}$ & $\begin{array}{l}31 / 11 \\
24 / 17\end{array}$ & $\begin{array}{l}18 \cdot 4 / 13 \cdot 5 \\
16 \cdot 8 / 24 \cdot 0\end{array}$ & $\begin{array}{l}162 / 64 \\
107 / 20\end{array}$ \\
\hline $\begin{array}{l}15 \\
16\end{array}$ & $\begin{array}{l}59 \\
53\end{array}$ & $\begin{array}{l}\text { M. } \\
\text { F. }\end{array}$ & $\begin{array}{l}\text { Aldactide } 3 \text { tabs. } \\
\text { Bethanidine } 110 \mathrm{mg} \\
\text { Methyldopa } 750 \mathrm{mg}\end{array}$ & $\begin{array}{l}190 / 113 \pm 18 \cdot 0 / 14 \cdot 4 \\
195 / 100 \pm 43 \cdot 8 / 15 \cdot 7\end{array}$ & $\begin{array}{l}161 / 94 \pm 4 \cdot 6 / 8 \cdot 6 \\
158 / 73 \pm 10 \cdot 3 / 3 \cdot 9\end{array}$ & $\begin{array}{l}29 / 19 \\
37 / 17\end{array}$ & $\begin{array}{l}15 \cdot 2 / 16 \cdot 8 \\
19 \cdot 0 / 17 \cdot 0\end{array}$ & $\begin{array}{l}131 / 53 \\
128 / 55\end{array}$ \\
\hline 17 & 21 & F. & $\begin{array}{l}\text { Aropanolol } 2 \mathrm{~g} \\
\text { Aldactide } 2 \text { tabs. }\end{array}$ & $150 / 86 \pm 9 \cdot 4 / 9 \cdot 6$ & $129 / 77 \pm 9 \cdot 4 / 3 \cdot 3$ & $21 / 9$ & $14 \cdot 0 / 10 \cdot 5$ & $92 / 44$ \\
\hline 18 & 57 & M. & Propanolol $120 \mathrm{mg}$ & $202 / 91 \pm 25 \cdot 7 / 21 \cdot 3$ & $160 / 61 \pm 9 \cdot 7 / 3 \cdot 4$ & $42 / 30$ & $20 \cdot 6 / 33 \cdot 0$ & $125 / 37$ \\
\hline Mean & \multicolumn{2}{|c|}{$48 \cdot 8$} & & $170 / 90$ & $139 / 72$ & $31 / 17$ & $18 \cdot 8 / 20 \cdot 1$ & $117 / 55$ \\
\hline
\end{tabular}

\section{Results}

Both systolic and diastolic pressures fell significantly during sleep in all 18 patients, the percentage fall in both values being about $20 \%$ irrespective of the level of the arterial pressure during waking and irrespective of hypotensive treatment (see table). With one exception the greatest fall in pressure occurred within two hours of the subject going to bed; in the exceptional case it occurred at five hours.

\section{Discussion}

We previously noted ${ }^{6}$ that there was a greater percentage fall in arterial pressure during sleep in four normotensive subjects who slept at home than in four who slept in hospital. This observation suggested that the patients either had not slept as well in hospital, though they seemed to be asleep, or were subconsciously aware of the hospital environment. Since no E.E.G.s were recorded we could not comment on the depth of sleep. Khatri and Freis, ${ }^{4}$ however, recorded haemodynamic events during sleep with a simultaneous E.E.G., and noted that the movements of their patients were limited even during sleep, suggesting that there was a subconscious awareness of the presence of the catheters. In another study ${ }^{5}$ subjects slept in the laboratory for three successive nights and intra-arterial recordings were made on the third night to minimize the "first night effect" noted by others, ${ }^{8}$ when sleep is atypical, with less rapid eye movement sleep, and more frequent changes in the depth of sleep. Our methods of recording direct arterial pressure allowed our subjects greater individual freedom and the procedure disturbed their normal routine very little; we believe that the arterial pressure recorded was truly representative of a normal 24-hour period in their lives. Since we recorded and averaged the pressure throughout this period the data provide a more realistic comparison of blood pressure during sleep and waking. Previous studies have usually compared blood pressure in the evening before sleep with that in the following night's sleep. It is probably more valid to average the whole waking record, as we did.

All three groups of patients showed an almost equal percentage fall in blood pressure during sleep, though the absolute fall depended on the height of the waking pressure. This percentage fall was greater than that recorded in some laboratory and hospital studies, ${ }^{4-6}$ but of the same magnitude as that recorded by Richardson et al. $^{3}$ in 17 healthy normotensive subjects $(19 \% /$ $17 \%$ ). These workers, however, noted the lowest pressure present for one minute and observed the depth of sleep at that time; if we had compared our lowest sleeping pressure with the waking blood pressure the fall would have been much greater.

Several reasons have been suggested for the fall in arterial pressure during sleep. The most likely seems to be that a reduction in sympathetic outflow leads to a reduction in peripheral resistance. ${ }^{4}$ This may be partly due to the increase in baroreflex sensitivity often seen in sleep. ${ }^{5} 9$ The effect on cardiac output seems to be variable ${ }^{4}$ and probably depends on the balance between peripheral resistance and cardiac contractility. From experiments in the cat Zanchetti's group have postulated that chemoreceptor reflexes may be important in controlling blood pressure during sleep. ${ }^{10}$ The importance of these neural mechanisms is seen in patients with phaeochromocytoma, in whom the blood pressure fall in sleep is absent or very small. ${ }^{11}$

Our results do not permit us to say what causes the fall in blood pressure during sleep, since we have no measurements of cerebral activity, cardiac output, or peripheral resistance. They suggest, however, that hypertensive patients do not have a higher centrally-induced vasoactive component, nor do hypotensive drugs seem to alter the pattern of blood pressure behaviour induced by sleep, though we did not compare the same subjects on and off treatment.

Perhaps surprisingly, treatment with neuronal blocking agents apparently does not alter the pattern of blood pressure changes in sleep. A parallel exists in the work of Guazzi et al., ${ }^{12}$ who found in cats that sympathetic nervous withdrawal was important in intact animals, but in sympathectomized animals a fall in blood pressure still occurred, possibly mediated via the adrenal medulla.

\section{References}

1 Smyth, H. S., D.PHIL., Thesis. University of Oxford, 1967.

2 Snyder, F., et al., fournal of Applied Physiology, 1969, 19, 417

3 Richardson, D. W. Honour, A. J., and Goodman, A. C., in Hypertension, ed. J. E. Wood III, vol. 16, p. 62. New York, American Heart Association, 1968. 
${ }^{4}$ Khatri, I. M., and Freis, E. D., Circulation, 1969, 39, 785.

5 Bristow, J. D., et al., Cardiovascular Research, 1969, 3, 476.

${ }^{6}$ Bevan, A. T., Honour, A. J., and Stott, F. H., Clinical Science, 1968, 36, 329.

${ }^{7}$ Littler, W. A., et al., British Medical fournal, 1972, 3, 76.

${ }^{8}$ Agnew, H. V., Webb, W. B., and Williams, R. L., Psychophysiology, 1966, $2,263$.
${ }^{9}$ Smyth, H. S., Sleight, P., and Pickering, G. W., Circulation Research, 1969, 24, 109.

10 Guazzi, M., Baccelli, G., and Zanchetti, A., American fournal of Physiology, $1968,214,969$

11 Littler, W. A., and Honour, A. J., Quarterly fournal of Medicine, 1974, 43, 441.

12 Guazzi, M., Ellsworth, O. T., and Freis, E. D., Cardiovascular Research, $1971,5,71$.

\title{
Detection of Cannabis Products in Urine by Radioimmunoassay
}

\author{
VINCENT MARKS， DERRICK TEALE， DENYS FRY
}

British Medical fournal, 1975, 3, 348-349

\begin{abstract}
Summary
A radioimmunoassay specific for the closed, three-ringed cannabinoid nucleus was used to detect and measure cannabis products in urine. Of the 475 urine specimens examined 82 came from hospital inpatients not suspected of taking drugs. None of these contained tetrahydrocannabinol cross-reacting cannabinoids (THC-CRC). The other 393 specimens were from patients known or suspected to be taking various drugs. Of these, 51 out of 162 from one hospital treatment clinic and 19 out of 50 from another were positive for THC-CRC. Out of 107 urine specimens from an independent drug treatment clinic 71 were positive for THC-CRC, as were 13 out of 74 specimens from patients in whom drug misuse was suspected or thought possible.
\end{abstract}

\section{Introduction}

Analysis of urine for drugs of abuse is commonplace in many clinical laboratories, ${ }^{1}$ the main emphasis in the U.K., as elsewhere, being on narcotics, amphetamines, and barbiturates. ${ }^{2-4}$ From time to time, however, other drugs, such as methaqualone, ${ }^{5}$ assume importance. Thin-layer chromatography constitutes the methodological basis of most drug-detection systems, but latterly immunoassay techniques have become important. ${ }^{\circ}$

Until recently no method of urine analysis was available for detecting cannabis use. Thus there is a dearth of reliable data on which to base present and future legislative policy regarding this drug. The introduction of an exquisitely sensitive, highly specific radioimmunoassay technique ${ }^{7-9}$ for measuring cannabis derivatives in blood and urine has enabled us for the first time to investigate cannabis use objectively.

\footnotetext{
Department of Biochemistry (Division of Clinical Biochemistry), University of Surrey, Guildford GU2 5 XH

VINCENT MARKS, D.M., F.R.C.PATH., Professor of Clinical Biochemistry DERRICK TEALE, PH.D., Research Fellow
}

Epsom Hospital Laboratories, West Park Hospital, Epsom DENYS FRY, B.SC., Biochemist

\section{Materials and Methods}

Urinary tetrahydrocannabinol cross-reacting cannabinoids (THCCRC) were measured by a radioimmunoassay technique specific for the closed, three-ringed cannabinoid nucleus. ${ }^{9}$ Specimens for analysis were selected by one of us. All urine samples received for analysis for drugs at the area laboratory at West Park Hospital between December 1974 and February 1975 were analysed for THC-CRC at regular intervals in number-coded batches at the University of Surrey. Included in random order were specimens of control urine. All the specimens came from patients living in the Greater London or Surrey areas and were collected between December 1974 and February 1975.

A total of 475 specimens were analysed. Of these, 82 were from hospital inpatients in whom drug abuse was not (and never had been) queried but in whom a quantitative measurement of urinary steroids, catecholamines, or some other endogenous product had been requested for diagnostic purposes; 319 came from two hospital treatment clinics (A and B) and one independent drug treatment clinic (C), for all of which the West Park Hospital laboratory provides a routine service for the analysis of drugs in urine $;^{10}$ and 74 came from other sources, including general medical outpatient departments, psychiatric clinics, and general practitioners' surgeries, with a request for routine analysis for drugs. This last, miscellaneous group included 17 specimens from eight residents of a hostel for former drug addicts. A condition for entry to and continued residence at the hostel is complete abstinence from habit-forming drugs, and to ensure compliance with this rule urine samples are tested regularly for narcotics, amphetamines, and barbiturates.

For this investigation urine samples containing less than $10 \mu \mathrm{g}$ of THC-CRC per 1 of urine were regarded as negative. More than a third of the samples from the drug treatment clinics came from patients who provided two or more specimens.

\section{Results}

All 82 urine specimens from the hospital inpatients were negative for cannabis (see fig.). Of the 162 specimens from clinic A and the 50 from clinic B $51(31 \%)$ and $19(38 \%)$, respectively, were positive for THC-CRC; $71(66 \%)$ of the 107 specimens from clinic C contained THC-CRC, as did $13(18 \%)$ of the 74 "miscellaneous" specimens. Investigation into the origin of the THC-CRC-positive specimens in the miscellaneous group disclosed that six of them came from the rehabilitation hostel and were provided by three people.

Altogether 32 patients provided urine specimens on three or more days. The results of quantitative analysis of the 113 specimens so provided are shown in the table.

\section{Discussion}

The radioimmunoassay used here is specific for the three-ringed cannabinoid nucleus. ${ }^{9}$ It does not distinguish between $\Delta^{9}$-THC, the most pharmacologically active natural cannabinoid, and its 